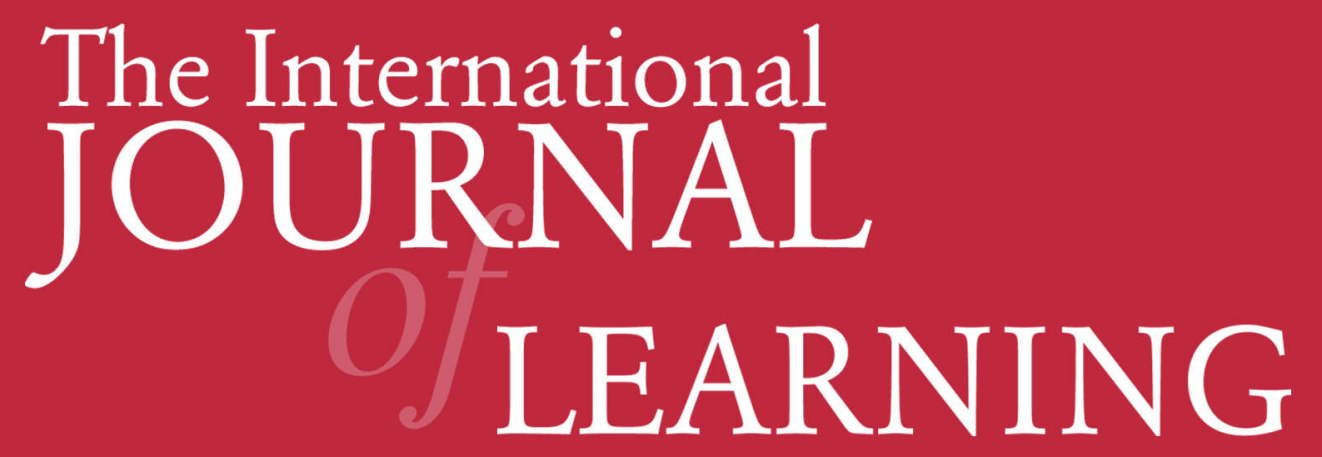

Identifying Effective Structural Dimensions for Course Portals

Catherine Dwyer Jeanine Meyer 
INTERNATIONAL JOURNAL OF LEARNING

http://www.Learning-Journal.com

First published in 2005 in Melbourne, Australia by Common Ground Publishing Pty Ltd www.CommonGroundPublishing.com.

(C) 2005 (this paper), the author(s)

(C) 2005 (selection and editorial matter) Common Ground

All rights reserved. Apart from fair use for the purposes of study, research, criticism or review as permitted under the Copyright Act (Australia), no part of this work may be reproduced without written permission from the publisher. For permissions and other inquiries, please contact <cg-support@ commongroundpublishing.com>.

ISSN: 1447-9494 (print), 1447-9540 (online)

Publisher Site: http://www.Learning-Journal.com

The INTERNATIONAL JOURNAL OF LEARNING is a peer refereed journal. Full papers submitted for publication are refereed by Associate Editors through anonymous referee processes.

Typeset in Common Ground Markup Language using CGCreator multichannel typesetting system http://www.CommonGroundSoftware.com. 


\title{
Identifying Effective Structural Dimensions for Course Portals
}

\author{
Catherine Dwyer, Pace University, United States of America \\ Jeanine Meyer, Purchase College, United States of America
}

\begin{abstract}
Modern university courses are brimming with content - multimedia, PowerPoint presentations, online tutorials, web resources, not to mention the standard text and face to face meetings. Are we overwhelming our students, force feeding them material? How can we integrate all these individual pieces? Are we asking too much of our faculty by giving too many choices? Course designers and instructors face a great challenge when trying to combine multi-modal disparate course components. Standard course management tools serve as primitive containers for course content, with minimal flexibility or ability to present a multi-dimensional course structure. How can we improve course management tools to optimize the cornucopia of content at our disposal? This paper proposes the key functional requirement is the ability to construct and present course content along a variety of dimensions. The critical dimensions are temporally-based-material for a particular time period, content-based-material related to a specific topic, activity-based-required for a paper or exam, and cognitive-based - degree of difficulty or complexity. The mechanism for improved course portal organization is the ability for instructors to present and students to navigate course content through these different dimensions.
\end{abstract}

Keywords: Instructional design, Online learning, Information overload, Cognitive load theory

\section{Introduction}

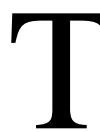

JHE WIDESPREAD DISTRIBUTION of Internet access has greatly increased the ability of instructors to distribute supplemental course material through a web site or course portal. The sources for this extra content can be material produced by the instructor, resources from other web sites, or from textbook publishers.

The material available is often very high quality and richly varied, providing depth and rigor to the learning experience. For example, the Shelly Cashman Discovering Computers Series has tutorials created in Flash, crossword puzzles and practise tests that are graded on the spot available for each chapter of the text (http://www.scsite.com/dc2005/). The Massachusetts Institute of Technology has made available extensive course materials for dozens of its courses (http://ocw.mit.edu/OcwWeb/index.htm).

The issue is not managing the quality of the material but the sheer quantity available. As the American comedian George Carlin explained, we have "too much stuff." (Carlin, 2005) As more and more material is added to courses, students can be overwhelmed by "information overload," which shuts down their capacity to absorb new information. This is the exact opposite of our intention as instructors when we add this material. The goal is to enrich learning - instead, information overload freezes it in place.

Therefore, the instructor or course designer should keep in mind the danger of information overload, and include or allow for student strategies to over- come it. Hiltz and Turoff suggest that information overload can be mastered through the use of structure (Hiltz, 1985). Especially important are structures that are developed by the course or group participants, arising organically from the nature of the material or the group (Turoff, 1999).

Although information overload is most associated with the Internet, it is certainly possible to induce this state without the use of a computer. One explanation for this comes from Cognitive Load Theory (Paas, 2003), which posits that human cognitive architecture is made up of a small working memory, supported by long term memory. Working memory is where all conscious cognitive processing occurs. Long term memory contains information organized into schemas - "cognitive structures that incorporate multiple elements of information into a single element with a single function." (Paas, 2003) For example, learning a new language will quickly fill up working memory, but riding a bicycle, a skill retrieved from long term memory, can be carried out by adults who have not ridden in years.

Cognitive load theory not only explains the frequency of information overload, it also suggests instructional techniques that minimize cognitive load (i.e. content in working memory), and maximize the ability to create schema and facilitate the incorporation of new concepts into long term memory.

Cognitive load theory argues that instructional designers can take advantage of germane or effective cognitive load (Paas, 2003). Germane cognitive load refers to the manner in which information is presented to learners. It can enhance learning by reducing 
working memory resources needed to facilitate search, and encourages the development of schema acquisition and automation. It is only through schema acquisition that long term learning occurs.

\section{Adding Effective Structural Dimensions}

Organization and structure will help bring order to the vast quantity of material available, and enable students to benefit from the resources available. For example, all the resources associated with a particular topic can be organized in one location. Or all the readings for a week can be organized together as well.

The problem is that the most popular course management software does not provide robust tools to enable the instructor to organize their material. For example, Blackboard (www.blackboard.com), a widely used course management system, does not include a search function to allow instructors or students to find resources within a portal. Instructors can organize material by hand first by content and then by due date, but if a changes occur, the instructor has to make updates in multiple locations.
The critical functionality that can help solve this problem is the ability to define dimensions for a course portal that serve as organizing mechanisms. A dimension is defined as a physical property that represents a fundamental structural element. In this context, the term dimension is generalized from the standard meaning of height, width, and depth, to any property that represents a fundamental structural element. Identifying and using dimensions provide a way for instructors and course designers to structure content and allow students to apply sense-making, encouraging the formation of schema that enable long term learning. The addition of tools that allow designers to define and add dimensions would help provide cognitive roadmaps into complex materials.

The use of dimensions as an organizing principle is borrowed from architecture, biology, and other sciences. For example, an architectural model demonstrates the relationship of a new buildings to its neighbours (see Figure 1), and the famous DNA double helix captures the structure of genetic material (see Figure 2).

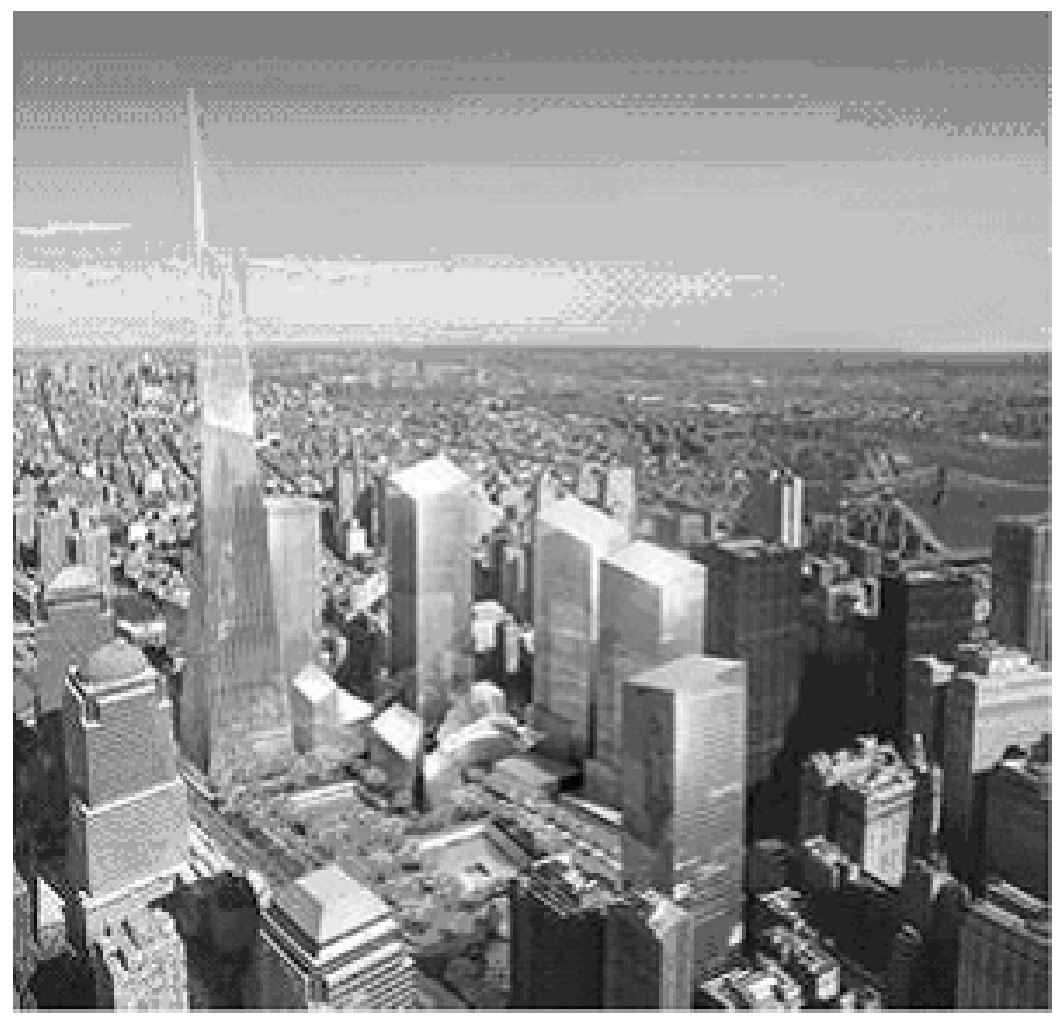

Figure 1: Model for New World Trade Center Site Relates New Buildings to Existing Structures 


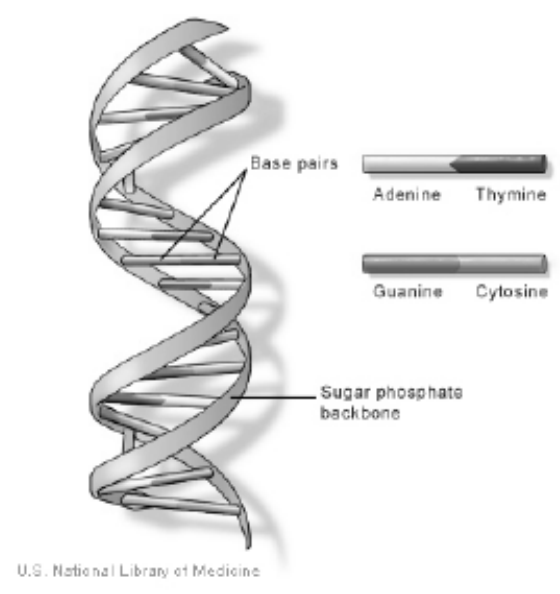

Figure 2: DNA Model Explains Structure of Genetic Material.

Although dimensions can help, they must be selected carefully. Their meaning should be intuitive and easy to understand. Otherwise they may cause extraneous or ineffective cognitive load, which occurs when instructional procedures are confusing or distracting (Paas, 2003).

The following dimensions are proposed for addition to course portals:

- Temporally based - course content is organized by week or class in chronological order

- Content based - material related to a specific topic

- Activity based - material tied to an ongoing activity (project) or exam

- Cognitively based - material organized based on its complexity or level of difficulty. Cognitive dimensions are modelled on Bloom's taxonomy, starting with knowledge, then comprehension, application, analysis, synthesis, and finally evaluation. (Bloom, 1954)

These dimensions are suggested because their meaning is clear and intuitive, and, most importantly, relate to typical student concerns. By using familiar and intuitive dimensions to organize material, the instructional designer can take advantage of germane cognitive load, and assist students in forming schema to make connections between concepts and form schema that enable long term learning.

\section{Functional Requirements for Adding Dimensions}

Instructors can already organize their material and present it in various dimensions. The problem is this must be done "by hand." In other words, the instructor can create a unit called "week 5," then add in all the relevant material for week 5 into that folder. If the topic for that week is, for example, computer networking, the instructor can create a second unit labelled networking, and load up the material in that location as well.

This method is tedious, and it creates the difficult problem of managing duplicate copies of resources. This is the critical flaw in most course management systems. Content can be added anywhere in a course portal, and it is the job of the instructor to keep track of where it is placed and manage version control.

While it is tedious and difficult for humans to keep track of resource locations and manage version control, this is something computer software has mastered for decades. The relational database, first described by E.F. Codd in 1970 (Codd, 1970), is a powerful tool that can organize information around several dimensions, known in database applications as primary and foreign keys. For example, when you view your e-mail, you have the ability to sort it by date, author, subject, size, or other characteristics. This ability comes from the use of database software.

While database software is very powerful, it only works if a very important restriction is complied with - there must be only one copy of an element in the database. From that single copy, dimensions or keys are added as indices or pointers to the element.

Although popular course management systems such as Blackboard and WebCT (www.WebCT.com) internally depend on database software, the power of database features is not made available to instructional designers. In addition, no restriction is made on how many times the same element can be added to a course portal. If portals were managed as databases, then adding dimensions to a course portal would be very easy to implement. 


\section{Designing a Course Portal as a Database}

The most popular feature of course management systems such as Blackboard and WebCT is their ease of use by instructors inexperienced with web design. With very little training, an instructor can quickly put together a course portal using Blackboard or WebCT. Adding database features that restrict the way in which instructors can add resources may degrade the ease of use for these systems. So the mechanism for adding these features must be done carefully.

The ideal model for course portals with dimensions and database features is the iPod digital music player, created by Apple computer (www.apple.com).
Although digital music players, or MP-3 players, have been on the markets for several years, the iPod has quickly become the top seller, despite a higher price tag. This has been attributed to its "simple elegance." (Weiss, 2003)

An iPod is basically a database of songs. And like all other databases, it only stores one copy of a song, but sets up multiple dimensions the listener can use to access a song. For example, you can access a song through Artist, Genre, Composer, or Album. These intuitive dimensions combined with Apple's easy to use iTunes software means that you can store 5,000 songs on an iPod, and find any one of them within seconds. (see Figure 3)

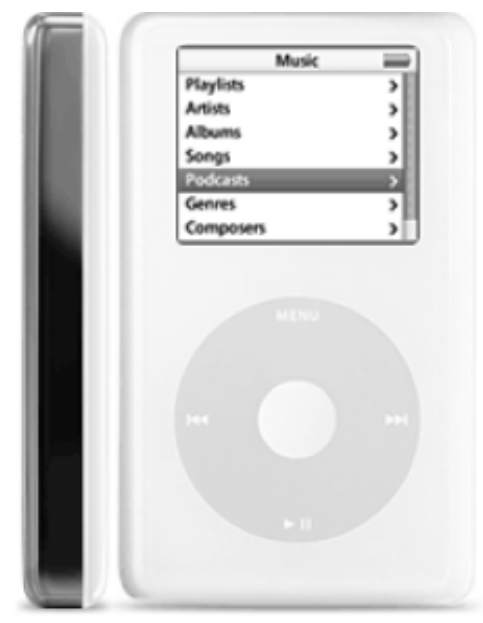

Figure 3: An Ipod is a Database of Songs.

How would the iPod model apply to a course portal? For example, your course portal could support a temporal dimension, listing each element required for a particular week. The temporal dimension could contain a reference to an activity, such as a project or exam. The actual details of the activity would be accessed through an activity dimension. In addition, content could be referenced by a content based dimension, as well as a cognitive based dimension.

The power of database software makes it very easy to add, modify and delete dimensions. Table 1 shows an example of how a Learning element can be added to a course portal organized with dimensions. In this example, the learning element is an audio PowerPoint presentation that introduces the students to a Web based resource, "The Simple Machine." This presentation is a tutorial on how to use a Java program that simulates the actions of a computer as it carries out programming instructions. In Table 1, the presentation is tagged as taking place in week 5, relating to the material on the Central Processing Unit (CPU), and required for the midterm. Any of these dimensions can be changed simply without affecting the Learning element.

Table 1

\begin{tabular}{|l|l|l|l|}
\hline Learning Element & Temporal dimension & Content Dimension & Activity Dimension \\
\hline $\begin{array}{l}\text { Introduction to the Simple } \\
\text { Machine (audio ppt) }\end{array}$ & Week 5 & $\begin{array}{l}\text { The Central Processing } \\
\text { Unit (CPU) }\end{array}$ & Midterm \\
\hline
\end{tabular}

An interesting and popular feature of the iPod is the "playlist," a custom sequence of songs that can be created by the owner of the iPod. The addition of a playlist feature to a course portal is an intriguing idea. It would give students the ability to define and save their own navigational paths through complex materials. For example, a student could create, independently or with the help of the instructor, a review plan for the final exam. This could apply to the whole course or could be "what I need to review and/or do 
to learn X". This ability to manipulate and customize the presentation of instructional material has tremendous potential as a learning aid for students.

\section{Discussion}

An advantage to the development of this tool is the fact that instructors and course designers are already developing and using these dimensions in their courses. Tools would make this process much easier and therefore more widespread. The database, one of the most powerful types of software developed to date, is a mature technology. Applying it to course development is not a giant leap. This has the potential to develop more robust course materials. Students can also define their own navigational paths through a course. The learning elements can consist of Word documents, PowerPoint presentations, web sites, or simple text files. This approach also facilitates the addition of a search mechanism, which would be a very welcome addition to course management systems.

The suggestions in this paper would benefit from, but are not dependent on the current research underway on the definition of "learning objects." A learning object is a re-usable unit of instruction. The idea behind learning objects is to decompose curricula into "atomic-level" components, which become resources for a course (Hodgins, 2005). This paper's solution does not require that instructors include content according to a particular format; it only requires file types that can be handled by a browser.

One disadvantage of this approach is that it does not address how to integrate online asynchronous course discussions into these dimensions. Since course discussion is a critical part of a successful online course (Hiltz, 2005), this is a serious limita- tion. In addition, the dimensions cannot just serve as buckets or containers for material. There must be a simple mechanism for sorting and managing elements within a dimension. This method also requires a new conceptual model of course development for instructors and designers, who have to re-think the way they organize their course materials.

\section{Conclusion}

For nearly any topic you can think of, vast amounts of information is available with a single query to a search engine. Here lies the paradox of the Internet's potential for education - without organization and structure, the quantity of resources retrievable through a search engine can actually reduce learning.

Instructors can easily find many excellent resources to supplement their course portals. They are often like kids in a candy store, adding on more and more. Even if the quality of the additional material is excellent, it often triggers the opposite of the intended effect. Students will quickly find that too much material creates a stressful cognitive load.

Course management systems currently are designed so that it is very easy to add material to a course portal, but very difficult to organize and structure it. This paper proposes that course management software add database functionality to their systems, and allow instructors and course designers to define dimensions that highlight navigation paths through complex materials. The suggested dimensions are temporal-based, content-based, activitybased, and cognitively-based. These dimensions are very intuitive, and would be easy for students to follow. While this is not a complete solution to the difficulties involved in organizing course content, it is a practical and readily implemented first step.

\section{References}

Bloom, B. (1954). Taxonomy of educational objectives. New York: Longmans, Green.

Carlin, G. (2005). http://www.georgecarlin.com/home/home.html.

Chandler, P., Sweller,J. (1991). Cognitive Load Theory and the Format of Instruction. Cognition and Instruction, 8, 293332.

Clark, J. (2000). Collaboration Tools in Online Learning Environments. JALN, 4(1).

Codd, E. F. (1970). A Relational Model of Data for Large Shared Data Banks. Communications of the ACM, 13(6), $377-$ 387.

Hiltz, S. R., Goldman, Ricki (Ed.). (2005). Learning Together Online. Mahwah, New Jersey: Lawrence Erlbaum Associates.

Hiltz, S. R., Turoff, Murray. (1985). Structuring computer-mediated communication systems to avoid information overload. Communications of the ACM, 28(7), 680-689.

Hodgins, W. (2005). Standard for Information Technology --Education and Training Systems -- Learning Objects and Metadata. http://ltsc.ieee.org/wg12/: IEEE Learning Technology Standards Committee.

Paas, F., Renkl, Alexander, Sweller, John. (2003). Cognitive Load Theory and Instructional Design: Recent Developments. Educational Psychologist, 38(1), 1-4.

Turoff, M., Hiltz, Starr Roxanne, Bieber, Michael, Fjermestad, Jerry, Rana, Ajaz. (1999). Collaborative Discourse Structures in Computer Mediated Group Communications. Journal of Computer Mediated Communications, 4(4).

Weiss, A. (2003). Changing of the Guard. NetWorker, 7, 18-24. 


\section{About the Authors}

Prof. Catherine Dwyer

Professor Catherine Dwyer is a member of the information systems faculty at Pace University, where she received the University Award for Distinguished Faculty Service this past December for her work as the developer of online materials for an introduction to computing course. She has developed curricula for a range of online courses, and has presented at national conferences on a variety of computing topics. Professor Dwyer is the author of several papers on computer science pedagogy, instructional technology, and (with Jeanine Meyer) a textbook on programming, "Programming Games using Visual Basic", Course Technology, 2001.

Dr. Jeanine Meyer

Jeanine Meyer worked as a researcher, research manager and research consultant at IBM before joining academia at Pace University and now Purchase College/SUNY. She has written or co-authored 3 textbooks. 
THE INTERNATIONAL JOURNAL OF LEARNING

EDITORS

Mary Kalantzis, RMIT University, Australia.

Bill Cope, Common Ground, Australia.

EDITORIAL ADVISORY BOARD

Michael Apple, University of Wisconsin-Madison, USA.

David Barton, Lancaster University, UK.

James Paul Gee, University of Wisconsin-Madison, USA.

Brian Street, King's College, University of London, UK.

Kris Gutierrez, University of California, Los Angeles, USA.

Scott Poynting, University of Western Sydney, Australia.

Gunther Kress, Institute of Education, University of London.

Ruth Finnegan, Open University, UK.

Roz Ivanic, Lancaster University, UK.

Colin Lankshear, James Cook University, Australia.

Michele Knobel, Montclair State University, New Jersey, USA.

Nicola Yelland, RMIT University, Australia.

Sarah Michaels, Clark University, Massachusetts, USA.

Richard Sohmer, Clark University, Massachusetts, USA.

Paul James, RMIT University, Melbourne, Australia.

Michel Singh, University of Western Sydney, Australia.

Peter Kell, University of Wollongong, Australia.

Gella Varnava-Skoura, National and Kapodistrian University of Athens, Greece.

Andeas Kazamias, University of Wisconsin, Madison, USA

Ambigapathy Pandian, Universiti Sains Malaysia, Penang, Malaysia.

Giorgos Tsiakalos, Aristotle University of Thessaloniki, Greece.

Carey Jewitt, Institute of Education, University of London, UK.

Denise Newfield, University of Witwatersrand, South Africa.

Pippa Stein, University of Witwatersrand, South Africa.

Zhou Zuoyu, School of Education, Beijing Normal University, China.

Wang Yingjie, School of Education, Beijing Normal University, China.

Juana M. Sancho Gil, University of Barcelona, Spain.

Manuela du Bois-Reymond, Universiteit Leiden, Netherlands.

Mario Bello, University of Science, Technology and Environment, Cuba.

Miguel A. Pereyra, University of Granada, Spain.

José-Luis Ortega, University of Granada, Spain.

Daniel Madrid Fernandez, University of Granada, Spain.

Francisco Fernandez Palomares, University of Granada, Spain.

ASSOCIATE EDITORS, 2005

Visit: http://www.Learning-Journal.com

SCOPE AND CONCERNS

Visit: http://www.Learning-Journal.com

SUBMISSION GUIDELINES

Visit: http://www.Learning-Journal.com

INQUIRIES

Email: cg-support@ commongroundpublishing.com 